\title{
Fagerstrom Test for Nicotine Dependence
}

National Cancer Institute

\section{Source}

National Cancer Institute. Fagerstrom Test for Nicotine Dependence. NCI Thesaurus.

Code C70989.

A standard instrument for assessing the intensity of physical addiction to nicotine. 